\title{
Advances in diagnosis, clinical care, research, and treatment in retinopathy of prematurity
}

\author{
This article was published in the following Dove Press journal: \\ Eye and Brain \\ 19 May 2016 \\ Number of times this article has been viewed
}

\author{
M Elizabeth Hartnett ${ }^{1-3}$ \\ Antonio Capone $\mathrm{Jr}^{4,5}$ \\ 'Vitreoretinal Surgery, John A. \\ Moran Eye Center, ${ }^{2}$ Department \\ of Ophthalmology, ${ }^{3}$ Department \\ of Neurobiology and Anatomy, and \\ Pediatrics, University of Utah, Salt \\ Lake City, UT, ${ }^{4}$ Associated Retina \\ Consultants, Royal Oak, ${ }^{5}$ Department \\ of Ophthalmology, Oakland \\ University William Beaumont Hospital \\ School of Medicine, Auburn Hills, MI, \\ USA
}

The appearance of retinopathy of prematurity (ROP) has changed throughout the world and since the first description of "retrolental fibroplasia" in 1942. However, despite advances in neonatal care and the abilities to improve the survival of ever younger and smaller premature infants, ROP remains a leading cause of childhood blindness worldwide. We know that ROP is complex in that it is influenced by genetic predisposition, epigenetic regulation, and environmental risks. It is strongly associated with extreme degrees of prematurity, and the "phenotype" of ROP depends on resources available to support premature infants with adequate nutrition and regulation of oxygen, as examples. New studies also suggest that what is seen in the preterm infant retina may portend later neurodevelopmental outcomes. Therefore, we believe this is a needed time to revisit ROP and provide a thematic issue focused on ROP from several perspectives.

In this issue, we present articles from several perspectives of ROP involving clinical, basic science, screening and treatment, and connections between the brain and retina. Dr Graham Quinn will describe how ROP differs throughout the world in part based on resources for preterm care. Dr Julia Shulman will describe current screening and treatment of premature infants with severe ROP in the US. Telemedicine approaches to screen infants for ROP in the US will be discussed by Drs Michael Trese and Darius Moshfeghi, and those used in rural India, by Dr Anand Vinekar. It is necessary to understand mechanisms of disease in ROP before determining potential forms of treatment, and models of oxygen-induced retinopathy have been essential. Drs Patricia D'Amore, Kip Connor, and Clifford Kim will describe the mouse model, which permits the use of genetically modified mice. The beagle model is useful to assess potential human pharmacologic strategies and Dr Gerard Lutty and Scott McLeod will discuss the model as it was used to target VEGF. Dr Haibo Wang will then discuss the rat model of oxygeninduced retinopathy, which recapitulates fluctuations in oxygenation seen in premature infants, and what has been learned by using it to understand mechanisms of aberrant intravitreal neovascularization. Dr Lois Smith will discuss current approaches that are being tested to prevent ROP by promoting vascularization of the avascular retina, including the potential role of lipid metabolites or IGF-1. Dr Maria Grant, along with Thao Le Phuong Trinh, Sergio Li Calzi, and Lynn Shaw, will describe the use of stem or progenitor cells to promote vascular repair from oxygen and other stresses in the premature retina. Dr Kim Drenser will describe the WNT pathway in normal and aberrant retinal vascularization. Finally, the intersection between angiogenesis and the
Correspondence: M Elizabeth Hartnett Vitreoretinal Surgery, John A. Moran Eye Center, 65 Mario Capecchi Drive, Salt Lake City, UT 84I32, USA Email me.hartnett@hsc.utah.edu
Eye and Brain 2016:8 27-29

(c) (1) (2) () 2016 Hartnett and Capone. This work is published and licensed by Dove Medical Press Limited. The full terms of this license are avalable at https://www.dovepress. (c). the work you hereby accept the Terms. Non-commercial uses of the work are permitted without any further permission from Dove Medical Press Limited, provided the work is properly attributed.

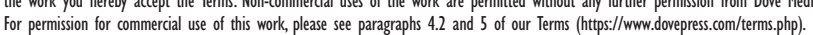

Dovepress

http://dx.doi.org/10.2147/EB.SI05319 
neurons of the retina and central nervous system and vision will be addressed. Drs Anne Fulton, Anne Moskowitz, and Ron Hansen will describe retinal and visual development in ROP. Dr Helen Hittner will describe the effects of anti-VEGF treatment on refractive development in ROP. Drs Cynthia Toth, Adam Rothman, Shwetha Mangalesh, and Xi Chen will discuss optical coherence tomography of the retina and the potential impact on neurodevelopment.

Besides the articles described briefly, we wish also to describe a few additional points to round out this thematic issue. First, some historical context on ROP: at the time of its initial description as retrolental fibroplasia, early stages of ROP were largely unknown, because visualizing the retina was limited - indirect ophthalmoscopy was not widely adopted, and there was limited ability to image or even view the peripheral retina, as we have now, using wide-angle cameras. Furthermore, the International Classification of ROP had not been developed. It is, therefore, unclear what stage(s) of ROP retrolental fibroplasia represented. Based on articles from that time period, many believe retrolental fibroplasia represented current day cicatricial stages of Stage 4 or 5 ROP. Then, infants who developed retrolental fibroplasia were of older gestational ages and larger birth weights than those who develop severe ROP currently in the USA. Part of the reason for the change in appearance of ROP, therefore, may be related to the stage of development of the retina, and its susceptibility to disordered and aberrant development from different external stresses and genetic predisposition. The stage of development includes that of developing neural and glial cells and their effects on the developing vasculature through the release of trophic factors or of other neuroor glial-vascular connections. Another reason relates to improvements in nutrition and in regulation and monitoring of oxygen levels in the preterm infant, and these resources vary throughout the developing world. When considering the many stresses to the preterm infant, eg, oxidative stress, nutrition, and poor growth, oxygen has been one of the most historically discussed stresses associated with ROP. ${ }^{1,2}$

At its first appearance as retrolental fibroplasia, premature infants were exposed to $100 \%$ inspired oxygen, because there were no technical methods to reliably regulate and monitor oxygen levels. Experimental and clinical scientists discovered that high oxygen at birth was the main culprit for retrolental fibroplasia. These scientists included experimental scientists, Michaelson and Ashton, and clinical scientist, Arnall Patz, ${ }^{3}$ who performed a clinical trial that showed that high oxygen use at birth was associated with retrolental fibroplasia. Efforts then included ones to develop the technology and implement methods to regulate and monitor oxygen through several methods, including transcutaneous oxygen monitoring, and currently by oxygen saturation. In concert with these efforts were advances in overall neonatal care that led to the survival of extremely low gestational age and low-birth-weight infants. Too low oxygen was also a concern, so balancing oxygen level with the degree of prematurity and other morbidities associated with prematurity was important. ${ }^{1,2}$ Subsequent studies tested the role of different oxygen levels provided at various post-gestational ages, but to younger infants than most of those surviving premature birth in the 1940s and 1950s. The Supplemental Therapeutic Oxygen for Prethreshold Retinopathy of Prematurity (STOP-ROP) study found that oxygen saturation targets of $96 \%-99 \%$ compared to $89 \%-94 \%$ starting at the diagnosis of prethreshold ROP did not increase risk of threshold ROP (defined as severe ROP at that time), but had some pulmonary morbidity. ${ }^{4}$ Other studies, such as the Surfactant, Positive Airway Pressure, Pulse Oximetry Randomized Trial (SUPPORT) found lower risk of severe ROP in infants at $85 \%-89 \%$ oxygen saturation than $91 \%-95 \%$, but there was concern for increased mortality in the lower oxygen saturation target. ${ }^{5}$ The Benefits of Oxygen Saturation Targeting II (BOOSTII) study found similar results, but the Canadian Oxygen Trial (COT) found no difference in severe ROP or mortality between the two oxygen saturation targets. ${ }^{6,7}$ There is currently no consensus among neonatologists regarding the levels of oxygen saturation to optimize the overall health of premature infants and to reduce the risk of severe ROP.

In attempting to stay within confines of oxygen saturation targets, some have suggested that oxygen swings occur when adjusting inspired oxygen levels to narrow windows of saturation limits. Several studies have postulated that fluctuations in oxygen levels may be more, or at least as much of a concern, for severe ROP. ${ }^{1,2,8}$ It is not possible to study the effects of oxygen stresses at the molecular level in the developing retina of premature infants. Therefore, several models of oxygen-induced retinopathy have been developed. Two are well described in this thematic journal and focus on high levels of oxygen recapitulating which occurs at the time of birth. Another important model is the rat model of fluctuating oxygen levels. This model was developed by Penn and introduces newly born rat pups whose retinal vasculature is incompletely developed to inspired oxygen levels that fluctuate between $50 \%$ and $10 \%$ every 24 hours. ${ }^{9,10}$ The inspired oxygen translates to arterial oxygen levels similar to transcutaneous oxygen extremes that human preterm infants at risk 
of severe ROP experience. This model may reflect ongoing oxygen stresses that premature infants experience during their courses in the newborn intensive care units. The model creates an appearance similar to zone 2, Stage 3, severe ROP. Limitations in the ability to study molecular mechanisms using the rat model have been addressed through the use of gene therapy methods and cell specific promoters to knock down compounds of interest within the retina. ${ }^{11,12}$

There is also increasing evidence that genetic predisposition plays a role in ROP. A number of studies found candidate genes associated with ROP or severe ROP in particular phenotypic groups. Many of these studies were limited as to sample sizes, infant inclusion criteria over broad ranges of gestational ages and birth weights, limited geographic locations, and potential variability in diagnostic accuracy. A US multicenter study from the Neonatal Research Network studied approximately 1,000 infants born with birth weight $<1,000$ g (extremely low birthweight) and found variants in intronic regions of the gene encoding BDNF associated with severe ROP. ${ }^{13}$ Other studies have also found associations with factors within the WNT signaling pathway, including FZD4, associated with growth impairment and ROP. ${ }^{14}$ These findings support the line of thinking that neurovascular connections play a role in the development with ROP.

We invite you to read the contributions to this thematic series and hope you will find the articles valuable and enjoyable.

\section{Acknowledgment}

This work was supported by the National Institutes of Health R01 R01EY015130 and R01EY017011 to MEH and an Unrestricted Grant from Research to Prevent Blindness, Inc., New York, NY, USA to the Department of Ophthalmology and Visual Sciences, University of Utah.

\section{Disclosure}

The authors report no conflicts of interest in this work.

\section{References}

1. Hartnett ME, Penn JS. Mechanisms and management of retinopathy of prematurity. $N$ Engl J Med. 2012;367(26):2515-2526.

2. Hartnett ME. Pathophysiology and mechanisms of severe retinopathy of prematurity. Ophthalmology. 2015;122(1):200-210.

3. Patz A, Hoeck LE, De La Cruz E. Studies on the effect of high oxygen administration in retrolental fibroplasia. I. Nursery observations. Am J Ophthalmol. 1952;35(9):1248-1253.

4. No authors listed. Supplemental Therapeutic Oxygen for Prethreshold Retinopathy Of Prematurity (STOP-ROP), a randomized, controlled trial. I: primary outcomes. Pediatrics. 2000;105(2):295-310.

5. SUPPORT Study Group of the Eunice Kennedy Shriver NICHD Neonatal Research Network, Carlow WA, Finder NN, et al. Target ranges of oxygen saturation in extremely preterm infants. $N$ Engl $J$ Med. 2010;362(21):1959-1969.

6. BOOST II United Kingdom Collaborative Group; BOOST II Australia Collaborative Group; BOOST II New Zealand Collaborative Group, et al. Oxygen saturation and outcomes in preterm infants. $N$ Engl J Med. 2013;368(22):2094-2104.

7. Schmidt B, Whyte RK, Asztalos EV, et al. Effects of targeting higher vs lower arterial oxygen saturations on death or disability in extremely preterm infants: a randomized clinical trial. JAMA. 2013;309(20): 2111-2120.

8. Hartnett ME, Lane R. Effects of oxygen on the development and severity of retinopathy of prematurity. JAAPOS. 2013;17(3):229-234.

9. Penn JS, Henry MM, Tolman BL. Exposure to alternating hypoxia and hyperoxia causes severe proliferative retinopathy in the newborn rat. Pediatr Res. 1994;36(6):724-731.

10. Penn JS, Henry MM, Wall PT, Tolman BL. The range of $\mathrm{PaO} 2$ variation determines the severity of oxygen induced retinopathy in newborn rats. Invest Ophthalmol Vis Sci. 1995;36(10):2063-2070.

11. Wang H, Smith GW, Yang Z, et al. Short hairpin RNA mediated knockdown of VEGFA in Müller cells reduces intravitreal neovascularization in a rat model of ROP. Am J Pathol. 2013;183(3):964-974.

12. Jiang Y, Wang H, Culp D, et al. Targeting Muller cell-derived VEGF 164 to reduce intravitreal neovascularization in the rat model of retinopathy of prematurity. Invest Ophthalmol Vis Sci. 2014;55(2):824-831.

13. Hartnett ME, Morrison MA, Smith S, et al. Genetic variants associated with severe retinopathy of prematurity in extremely low birth weight infants. Invest Ophthalmol Vis Sci. 2014;55(10):6194-6203.

14. Dailey WA, Gryc W, Garg PG, Drenser KA. Frizzled-4 Variations Associated with Retinopathy and Intrauterine Growth Retardation: A Potential Marker for Prematurity and Retinopathy. Ophthalmology. 2015;122(9):1917-1923.

\begin{abstract}
Dove Medical Press encourages responsible, free and frank academic debate. The content of the Eye and Brain 'Editorial' section does not necessarily represent the views of Dove Medical Press, its officers, agents, employees, related entities or the Eye and Brain editors. While all reasonable steps have been taken to confirm the content of each Editorial, Dove Medical Press accepts no liability in respect of the content of any Editorial, nor is it responsible for the content and accuracy of any Editorial.
\end{abstract}

Eye and Brain

Dovepress

\section{Publish your work in this journal}

Eye and Brain is an international, peer-reviewed, open access journal focusing on clinical and experimental research in the field of neuroophthalmology. All aspects of patient care are addressed within the journal as well as basic research. Papers covering original research, basic science, clinical and epidemiological studies, reviews and evaluations,

Submit your manuscript here: http://www.dovepress.com/eye-and-brain-journal guidelines, expert opinion and commentary, case reports and extended reports are welcome. The manuscript management system is completely online and includes a very quick and fair peer-review system, which is all easy to use. Visit http://www.dovepress.com/testimonials.php to read real quotes from published authors. 